\title{
Tipologías de la intervención social con jóvenes
}

\section{Typologies of social intervention with young people}

\section{Tipologias de intervenção social com jovens}

\author{
Nemesio Castillo Viveros \\ Universidad Autónoma de Ciudad Juárez, Departamento de Ciencias Sociales, México. \\ nemesio.castillo@uacj.mx \\ https://orcid.org/0000-0001-9254-0183
}

\section{Resumen}

Este artículo comprende el proceso de intervención social de cuatro organizaciones de la sociedad civil que trabajan con jóvenes en contexto de violencia y vulnerabilidad en Ciudad Juárez, Chihuahua, México. Se realizó una clasificación de tres enfoques de intervención social: adaptativas, socioeducativas y sociocríticas. A partir de ahí se describe el proceso de intervención que desarrollan las organizaciones. En la literatura sobre intervención social se observó un enfoque de acción general y universal, sin embargo, a partir del trabajo de campo, se encontró que la intervención social en contextos de violencia debe centrarse más en el seguimiento y acompañamiento a las y los jóvenes. Además, es necesario que las y los jóvenes cuestionen sus prácticas sociales desde el contexto social en el que viven. Esta investigación es cualitativa, se hicieron cuatro grupos focales con jóvenes, uno por cada organización. Se hizo un análisis de categorías con la ayuda del software Atlas.ti versión 7.0.

Palabras clave: exclusión social y pobreza, intervención social, jóvenes, violencia, vulnerabilidad. 


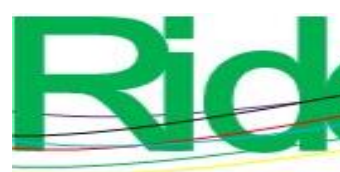

Revista Iberoamericana para la

Investigación y el Desarrollo Educativo

ISSN $2007-7467$

\section{Abstract}

This article understands the process of social intervention of four civil society organizations that work with young people in a context of violence and vulnerability in Ciudad Juárez, Chihuahua, Mexico. A classification is made of three social intervention approaches: adaptive, socio-educational and socio-critical, from there the process of intervention developed by organizations is described. In the literature on social intervention, a general and universal action approach was observed, however, based on fieldwork, it was found that social intervention in contexts of violence should focus more on the follow-up and accompaniment of young people. In addition, it is necessary for young people to question their social practices from the social context in which they live. The research focus is qualitative, there were four focus groups with young people, one for each organization. An analysis of categories was made with the help of Atlas.ti version 7.0.

Keywords: social exclusion and poverty, social intervention, youth, violence, vulnerability.

\section{Resumo}

Este artigo inclui o processo de intervenção social de quatro organizações da sociedade civil que trabalham com jovens no contexto de violência e vulnerabilidade em Ciudad Juárez, Chihuahua, México. Foi feita uma classificação de três abordagens à intervenção social: adaptativa, socioeducativa e sócio-crítica. A partir daí, é descrito o processo de intervenção desenvolvido pelas organizações. Na literatura sobre intervenção social, observou-se uma abordagem de ação geral e universal, no entanto, com base no trabalho de campo, verificou-se que a intervenção social em contextos de violência deve se concentrar mais no monitoramento e acompanhamento de jovens. Além disso, os jovens precisam questionar suas práticas sociais a partir do contexto social em que vivem. Esta pesquisa é qualitativa, foram realizados quatro grupos focais com jovens, um para cada organização. Uma análise de categoria foi feita com a ajuda do software Atlas.ti versão 7.0.

Palavras-chave: exclusão social e pobreza, intervenção social, juventude, violência, vulnerabilidade.

Fecha Recepción: Julio 2019

Fecha Aceptación: Mayo 2020 


\section{Introducción}

Este documento es resultado de un análisis de varias experiencias de intervención social en el contexto de Ciudad Juárez, Chihuahua. Concluimos que existen diversas formas de entender y desarrollar la intervención social. Las podemos clasificar en tres tipos: 1) aquellas que buscan fortalecer el sistema social, 2) las que parten del enfoque socioeducativo y 3) las intervenciones sociocríticas. Cada una de ellas puede obtener resultados en los individuos, grupos y comunidades de manera diferenciada. Las que se enfocan en el sistema son aquellas que buscan integrar a los sujetos a la sociedad a través de la adquisición de habilidades y capacidades; las intervenciones que se centran en lo educativo son aquellas que buscan, mediante la educación formal e informal, generar actitudes y comportamientos que les permitan a las personas ser capaces de entender la dinámica social; las intervenciones socioreflexivas, por último, son aquellas que permiten la transformación social de las prácticas de los individuos y las comunidades.

Desde una perspectiva social hay que entender que los problemas sociales se construyen, no surgen de manera natural. Ya lo dijeron Berger y Luckmann (2003): "La realidad se construye socialmente" (p. 11). Y es deber del investigador social analizar los procesos que permiten dicha construcción. Es en este contexto que tenemos que hablar de los momentos históricos de la intervención social, ya que los procesos sociales cambian y la realidad siempre exige nuevas teorías, metodologías y técnicas de intervención. Las intervenciones tienen un tiempo, un contexto y son de carácter local. Carballeda (2012) dice que en "sus orígenes, gran parte del sentido de la intervención en lo social está relacionada con el modo como cada época construye los perfiles de la transgresión” (p. 24). Entonces, debemos de hablar de experiencias y enfoques de intervención que obedecen a una época y contexto.

Actualmente, conceptos como pobreza, exclusión o vulnerabilidad se han ido analizando, explicando y han sido intervenidos en función del avance científico, lo que nos lleva a decir que hay diferentes formas de medirlos, evaluarlos e intervenirlos en función del contexto y época. Esas diferencias de intervención las podemos llamar paradigmas. Por ejemplo, los teóricos funcionalistas y marxistas tenían dos definiciones distintas del mismo problema, así como había diferencias profundas en las formas de intervención.

Tiempo atrás, en la época medieval, "la ayuda se desarrollaba prioritariamente a través de la comunidad y la familia. Al mismo tiempo, los sistemas gremiales desarrollaron modelos de previsión y protección social para los pertenecientes al gremio" (Losada, 2016, p. 18). La Iglesia y la caridad eran claves para atender las necesidades de los marginados. Con la entrada de la edad moderna, nace una nueva forma de asistencia social, la beneficencia pública, "cuyo 


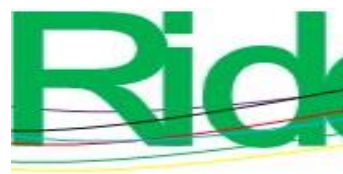

Revista Iberoamericana para la Investigación y el Desarrollo Educativo ISSN $2007-7467$

protagonismo pasa a los ayuntamientos" (Losada, 2016, p. 18). Finalmente, después de la Segunda Guerra Mundial, nace el estado de bienestar, a partir del cual se establece la asistencia social como un derecho.

Surge en un momento en el que las instituciones existentes no eran capaces de solucionar los problemas derivados de la pobreza y la desigualdad generados por la economía. Era una realidad que el mercado era incapaz de corregir estos errores y garantizar una distribución más equitativa de los recursos (Losada, 2016, p. 18).

\section{Enfoques de la intervención social}

De acuerdo con José Sáenz (2008), la intervención social “constituye ante todo un proceso de orden racional, pues se funda en una intención manifiesta de modificar o transformar una situación que se considera indeseable e injusta socialmente, ante todo para el grupo que la padece" (p. 189). Debemos entenderla como un proceso social que se piensa como racional únicamente para el grupo que la está implementando; para quien mira desde afuera puede parecerle lo contrario. Lo que está detrás son los intereses de a dónde se quiere llevar a las personas que van a formar parte de un proceso de intervención.

Aquí queremos mostrar que hay al menos tres estilos de entender la intervención social. Pudiera existir un mayor número, pero con la intención de hacer un recorte conceptual y epistemológico dentro de la producción científica que ha trabajado el tema, nos limitados a tres, ya mencionadas anteriormente: intervenciones prosistemas, intervenciones socioeducativas e intervenciones crítico-reflexivas.

Hay que tener presente que los científicos sociales y los especialistas en intervención social parten de una idea del sujeto. En ese sentido, las intervenciones sociales no son neutras. Hay un interés que, en primera instancia, no se manifiesta de manera natural respecto a la forma en que se justifica el discurso de la intervención. Se requiere de un análisis minucioso para saber cuál es el destino que se busca en las intervenciones. Adaptar al individuo, fortalecer el sistema o transformar el sistema.

El primer bloque de acciones, denominado prosistema o intervenciones adaptativas, busca adaptar al sujeto al sistema social: educarlo, capacitarlo y orientarlo para el trabajo, principalmente se busca que sea productivo. Así, con la intervención social legitimada por "la sociedad se convierte en objeto maleable, que se puede modelar, planificar, diseñar (...) hasta conseguir que se adapte, que encaje en ese modelo" (Ruiz, 2010, p. 17). Por lo que se trata de intervenir de manera consciente y dirigida. Es decir, el Estado tiene claro a dónde quiere llegar 


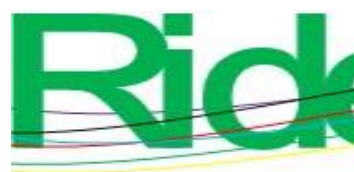

Revista Iberoamericana para la

Investigación y el Desarrollo Educativo

ISSN $2007-7467$

con la intervención social, llámese política pública o política social. "La sociedad no puede ser de cualquier manera, algunos tienen la obligación de determinar cómo debe ser" (Ruiz, 2010, p. 17).

Desde este enfoque, la intervención social se asume "como un conjunto de acciones y prácticas organizadas bajo la figura de una oferta de servicios alrededor de lo social" (Bermúdez, 2010, p. 56). Propiamente, se mira al usuario o beneficiario como pasivo. El Estado y agrupaciones civiles otorgan un conjunto de servicios para que el asistido se pueda desarrollar socialmente. Sin embargo, detrás no hay un "sustento teórico, pero sí con concepciones sobre quién es el otro, sobre la ayuda, cargado de buena voluntad e intuición” (Bermúdez, 2010, p. $58)$.

Las llamaríamos intervenciones adaptativas, o prosistema, porque tienen un carácter asistencial, se interviene desde el sentido común, no se hace previamente un diagnóstico riguroso de los problemas sociales donde se quiere intervenir. No se analizan ni las causas ni las consecuencias de los problemas sociales, ni tampoco se hacen procesos de evaluación de las intervenciones. Únicamente se busca asistir al beneficiario cuando tiene una necesidad inmediata. Pero lo fundamental no son sus características, lo que importa es a dónde llevan estas intervenciones. Se trata de procesos de adaptación y reproducción social, en el sentido de que son acciones inmediatas que no buscan modificar la actitud o comportamiento del beneficiario. Además, en ningún momento buscan modificar las relaciones de clases sociales o las estructuras sociales.

En cuanto al segundo enfoque, su nombre apropiado es intervenciones socioeducativas. ya que sostienen argumentos educativos e impulsan el desarrollo de procesos de participación social. Por supuesto, hay un amplio número de intervenciones bajo este enfoque. De alguna manera se espera que el Gobierno, sociedad y mercado colaboren en los procesos de intervención. "Es responsabilidad de todas las instancias que tienen responsabilidad en la respuesta educativa así como en las redes sociales y de salud poner los medios y recursos para que desde la educación se puedan abordar los problemas" (Gallardo, 2006, p. 1). Cabe señalar que no se proponen modificar las estructuras sociales o al sujeto, más bien perfeccionar al sistema. Según Gallardo (2006), para este tipo de acercamientos no basta con la participación de las instituciones educativas, sino que se requiere la "colaboración de otros sistemas como salud, bienestar social y justicia. Es necesario, por tanto la colaboración entre las diferentes redes complementándose, ya que la escuela sola no puede abordar una situación multiproblemática" (p. 2). También se habla de "la responsabilidad de toda la comunidad" (Escudero, 2011, p. 13). Y en esa misma línea, se habla de la familia como pieza clave del proceso de intervención: 


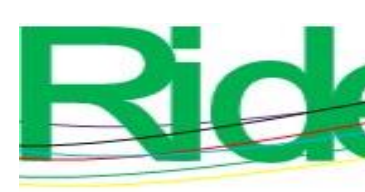

Revista Iberoamericana para la Investigación y el Desarrollo Educativo ISSN 2007 - 7467

Se considera pertinente resaltar el rol que cumple la familia en los espacios de las interrelaciones sociales, teniendo en cuenta que cada familia se encuentra permeada por condiciones y particularidades a nivel cultural, político y económico, y teniendo en cuenta su historicidad en la construcción de cada una de sus singularidades, tales como valores, costumbres, relaciones de poder, comunicación entre otras (Arnedo, Díaz y González, 2016, p. 32).

De manera concreta, se hace referencia a la "corresponsabilidad y participación: es preciso tener en cuenta la pluralidad de actores que trabajan en el ámbito social, y hacerles partícipes de la configuración de las políticas y actuaciones que se implementen" (Diputació Barcelona, 2009, p. 35).

Y por otro lado, se ve a la intervención como un proceso abierto de constante análisis. "Se aborda no tanto desde la búsqueda inmediata de soluciones como de iniciar procesos socioeducativos, integrales, flexibles y abiertos; con vocación transformadora" (Callado y Martínez, 2017, p. 286-287).

Se trata de un tipo de intervención donde existe la figura de un facilitador, o en su caso, promotor social, donde, con la intervención, se "pretende diseñar, desarrollar y evaluar las acciones desde la propia comunidad con el acompañamiento del facilitador promoviendo la movilización de los grupos miembros de una comunidad. Las acciones serán más eficaces cuanto más se logre involucrar" (Mori, 2008, p. 81).

Cabe señalar que dentro de este enfoque existe el interés por realizar diagnósticos para entender las necesidades sociales y posteriormente diseñar la intervención. Al menos se tiene una idea de que se debe realizar un diagnóstico, una planeación, una intervención y una evaluación del proyecto. En la primera fase de la intervención se debe hacer "una previa identificación de las características sociodemográficas, socioculturales, niveles educativos, sistemas de salud, necesidades, problemas, recursos y comportamientos comunales; ello nos guiará hacia la formulación de propuestas de desarrollo y alternativas de solución frente a situaciones adversas" (Mori, 2008, p. 83).

Se habla entonces de diseñar procesos educativos que puedan empoderar a los usuarios, pero dentro de los márgenes del fortalecimiento del sistema. Son intervenciones informadas, es decir, desde un inicio queda claro qué es lo que se quiere lograr con el proyecto de intervención. "Un proyecto de intervención social en miras a la construcción individual de autonomía y conocimientos, motivando a los/as adolescentes y jóvenes a cambiar y reforzar sus potencialidades, elementos para aportarle a la transformación social de su entorno" (Arnedo et al., 2016, pp. 24-25). En palabras de Díaz y Silva (2018), se entiende a la intervención como 
pensamiento crítico-dialéctico que permita dilucidar las contradicciones de capital-trabajo, ya que de la intervención se generan formas de ver y comprender el mundo, justificando la desigualdad social. Borgianni y Montaño (2000, p. 124) mencionan que se producen procesos de "segmentación, naturalización y deshistorización de la realidad social". Además, no existe una conexión entre "conocimiento y acción, entre teoría y práctica". Así pues, se trata de un “apriorismo metodológico" (Borgianni y Montaño, 200, p.32). Al desarrollar la intervención social de esta manera lo que en realidad estamos haciendo es creando una "técnica social, o en el mejor de los casos, a un conjunto de técnicas, a una tecnología, y como tal, fuerza productiva de carácter instrumental, simple medio para la reproducción del capital” (Guerra, 2007, p. 144).

Desde la perspectiva crítico-reflexiva, la intervención social tiene un alcance de mayor profundidad en relación con los cambios al sistema y a las prácticas sociales. Freire (1976) indica que toda intervención deberá enfocarse en una "verdadera praxis, reflexión y acción del hombre sobre el mundo para transformarlo" (p. 4). Poza et al. (2018), por su parte, apelan a una acción social que promueva escenarios de trabajo compartidos y procesos de inclusión juvenil, intentando dar respuesta a necesidades sociales $\mathrm{y}$, específicamente, aspirando a una legitimación pública y/o social, incidiendo en la interacción y participación de los jóvenes .

En particular se hace referencia a la introducción de un proyecto ético político donde se dé "la eliminación de toda forma de explotación, dominación y sometimiento, como sistema de convivencia social y de desarrollo de una ciudadanía substantiva” (Montaño, 2004, p. 9). El proceso de intervención debe ser siempre con una mirada crítica a las contradicciones entre capital y trabajo. La intervención social debería alterar las relaciones macroestructurales, entre los intereses de clases, teniendo, por lo tanto, un papel (ético-político) en tales relaciones. Finalmente, debe tener una función de cambio en la estructura social, y que evite a toda costa la reproducción del sistema y del statu quo (Montaño, 2004).

En las intervenciones crítico-políticas se generan procesos de diagnóstico, planeación, implementación y evaluación de programas o proyectos. Pero su característica principal es que la voz de los beneficiarios está presente en el diseño de los proyectos. En este tipo de intervenciones sociales hay un cuestionamiento de las prácticas sociales desde una mirada amplia, es decir, se discuten las prácticas del beneficiario, de la comunidad y al Estado. Se hace un análisis crítico de la realidad social, se busca entender los orígenes de la desigualdad y crear alternativas al modelo económico. Son procesos largos. De hecho, en lugar de nombrarle intervención, vendría mejor llamarle acompañamiento.

Por lo anterior, tendríamos que hablar de una diversidad de intervenciones sociales que hacen las organizaciones sociales e instituciones del Estado. De manera esquemática, la tabla 1 presenta una clasificación de los tres tipos de intervención social. 
Tabla 1. Enfoques y niveles de intervención

\begin{tabular}{|c|c|c|c|}
\hline $\begin{array}{ll}\text { Enfoques } & \text { de } \\
\text { intervención } & \end{array}$ & $\begin{array}{l}\text { Intervenciones } \\
\text { prosistemas }\end{array}$ & $\begin{array}{l}\text { Intervenciones } \\
\text { socioeducativas }\end{array}$ & $\begin{array}{l}\text { Intervenciones } \\
\text { crítico-reflexivas }\end{array}$ \\
\hline Participantes & Individual & Individual-colectivo & Comunitario \\
\hline $\begin{array}{l}\text { Responsables de } \\
\text { la intervención }\end{array}$ & Servidores públicos & $\begin{array}{l}\text { Facilitador-promotor } \\
\text { social }\end{array}$ & $\begin{array}{l}\text { Acompañamiento } \\
\text { comunitario }\end{array}$ \\
\hline $\begin{array}{ll}\text { Guías } & \text { de } \\
\text { intervención } & \end{array}$ & $\begin{array}{l}\text { Estudios } \\
\text { socioeconómicos }\end{array}$ & Diagnósticos sociales & $\begin{array}{l}\text { Reflexiones } \\
\text { colectivas }\end{array}$ \\
\hline Alcance & $\begin{array}{l}\text { Reproducción del } \\
\text { sistema }\end{array}$ & $\begin{array}{l}\text { Fortalecimiento del } \\
\text { sistema }\end{array}$ & Cambio de sistema \\
\hline $\begin{array}{l}\text { Origen de los } \\
\text { problemas } \\
\text { sociales }\end{array}$ & Persona & $\begin{array}{l}\text { Corresponsabilidad } \\
\text { Estado-Gobierno }\end{array}$ & $\begin{array}{l}\text { Sistema-comunidad- } \\
\text { persona }\end{array}$ \\
\hline Técnicas & Encuestas & $\begin{array}{l}\text { Técnicas cualitativas } \\
\text { y cuantitativas }\end{array}$ & Grupos de análisis \\
\hline Modelo & Asistencialismo & Asistencia social & $\begin{array}{l}\text { Modelo crítico } \\
\text { radical }\end{array}$ \\
\hline
\end{tabular}

Fuente: Elaboración propia

\section{Método}

El trabajo de campo se hizo con cuatro organizaciones de la sociedad civil. ${ }^{1}$ Las organizaciones se encuentran ubicadas en la zona norponiente y suroriente de Ciudad Juárez, Chihuahua. Tienen cerca de 30 años de experiencia en intervención social con jóvenes. Sus instalaciones están consolidados para recibir cerca de 100 jóvenes diarios. En sus instalaciones, además, existen áreas para la impartición de talleres de música, pintura, circo urbano, computación, español, matemáticas, entre otras. Atienden cerca de 80000 jóvenes que viven en condiciones de vulnerabilidad y en riego.

Partimos del supuesto de investigación de que las organizaciones de la sociedad civil están limitadas en cuanto a recursos económicos y humanos para realizar su labor con los jóvenes, lo que las lleva a generar estrategias a corto plazo y enfocadas en el entretenimiento y diversión, lo cual no permite cambios en las prácticas sociales de los jóvenes a largo plazo; sin embargo, a pesar de esas limitaciones, hay jóvenes que modifican sus conductas.

\footnotetext{
${ }^{1}$ Para garantizar el anonimato de las organizaciones de la sociedad civil se reservan los nombres.
} 


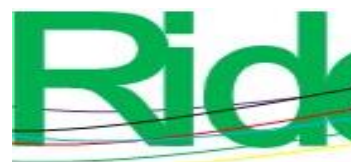

Revista Iberoamericana para la

Investigación y el Desarrollo Educativo

ISSN $2007-7467$

Las dimensiones de análisis que se plantean son las siguientes: apoyo en las organizaciones, familia, escuela, entretenimiento, diversión, autoestima, estrés, aspiraciones sociales y recomendaciones para las organizaciones de la sociedad civil.

Esta investigación tiene como objetivo mostrar la experiencia de intervención de cuatro organizaciones de la sociedad civil que trabajan con jóvenes en contextos vulnerables en Ciudad Juárez, Chihuahua, México. Analizamos la experiencia de los jóvenes en el proceso de intervención y acompañamiento por los educadores. Específicamente, nos enfocamos en jóvenes que desertaron de la escuela formal y que ahora están dentro de las organizaciones y están siendo apoyados para presentar sus exámenes de secundaria y preparatoria en el Instituto de Chihuahua de Educación para los Adultos (ICHEA), con el fin de culminar sus estudios de educación media superior. Para desarrollar esta investigación recurrimos a la técnica de grupos focales.

Como señala Miguel Aigneren (2002), los diálogos logradas mediante la técnica de grupos focales tienen como propósito registrar cómo los participantes elaboran grupalmente su realidad y experiencia. Para Aigneren (2002), una cuestión importante a considerar es que, como todo acto comunicativo, tiene siempre un contexto cultural y social, por lo que, en el análisis de la información recabada, se establece como prioridad la comprensión de esos contextos comunicativos y sus diferentes modalidades.

La técnica de los grupos focales plantea un ejercicio abierto y estructurado que la mayoría de las veces se desarrolla como una conversación grupal, en la cual el investigador plantea algunas temáticas y preguntas asociadas a algunos antecedentes que orientan la dirección de esta, de acuerdo con los propósitos de la investigación.

En este sentido, el grupo focal:

Se diferencia de una conversación coloquial porque el investigador plantea previamente las temáticas y, si es el caso, el tópico no se da por agotado retornando nuevamente una y otra vez ya que interesa captar en profundidad los diversos puntos de vista sobre el asunto discutido (Aigneren, 2002)

Esta técnica, bajo su modalidad grupal, se convierte también en un intercambio de experiencias, ya que generalmente cuando un participante percibe que sus interlocutores tienen una experiencia o una vivencia similar o conocimientos sobre el tema reacciona positivamente, ya que esta situación comunicacional retroalimenta su interés por el tema. En el caso específico de este ejercicio, se trabajó con grupos homogéneos, lo que permitió lograr el propósito mencionado. 


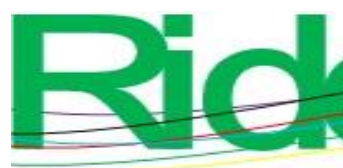

Revista Iberoamericana para la Investigación y el Desarrollo Educativo ISSN $2007-7467$

Korman (1986, citado en Aigneren, 2002) plantea que un grupo focal es una reunión de un grupo de individuos seleccionados por los investigadores para discutir y elaborar, desde la experiencia personal, una temática o hecho social que es objeto de investigación. Y siguiendo a este mismo autor, los grupos focales requieren de procesos de interacción, discusión y elaboración de acuerdos dentro del grupo acerca de unas temáticas que son propuestas por el investigador. Por lo tanto, interesa conocer cuál es el sentido que los y las participantes en los grupos focales le otorgan a sus prácticas, a través de un acercamiento comprehensivo a sus narrativas, en las que vierten y aportan su experiencia.

De esta manera, el punto característico que distingue a los grupos focales es la participación dirigida y consciente y unas conclusiones producto de la interacción y elaboración de unos acuerdos entre los participantes (Korman, 1986, citado en Aigneren, 2002).

Criterios de selección:

- $\quad$ Se hicieron un total de cuatro grupos focales; uno por cada organización.

- $\quad$ El criterio de selección es que estuvieran en algún programa que tiene cada organización de la sociedad civil.

- La participación en cada uno de los grupos focales fue de entre 6 y 12 participantes.

- $\quad$ Los grupos se desarrollaron entre los meses de mayo y junio de 2018.

\section{Resultados}

Dentro de este apartado abordamos las formas de intervención que desarrollan las organizaciones de la sociedad civil con los jóvenes en situación de violencia. Y se trata de dar respuesta a la siguiente pregunta: ¿qué tipo de formación y de acompañamiento necesitan los jóvenes que les permitan cuestionar sus prácticas sociales en contextos de violencia y vulnerabilidad? En un primer momento se aborda la opinión de los jóvenes respecto al apoyo que reciben de las organizaciones de la sociedad civil, la familia y la escuela. Y cerramos el apartado con lo que los jóvenes solicitan de las organizaciones y nuestra propuesta de intervención social. 


\section{La intervención social en las organizaciones}

Las categorías o códigos de análisis de la información recabada en el trabajo de campo se centran en lo puesto a continuación: apoyo en las organizaciones, familia, escuela, entretenimiento, diversión, autoestima, estrés, aspiraciones sociales y recomendaciones para las organizaciones de la sociedad civil. Con esas categorías de análisis responderemos a la pregunta de investigación relacionada con los tipos y retos de intervención social con jóvenes en contextos de violencia.

El trabajo de las organizaciones de la sociedad civil se encuentra vinculado al trabajo de la familia y la escuela. En esta primera parte vamos a dimensionar la opinión de los usuarios respecto al apoyo que reciben de las organizaciones. Las opiniones de los beneficiarios están un tanto divididas: algunos usuarios dicen recibir apoyo en las tareas escolares, otros mencionan que no lo reciben.

Uno de los participantes comentó que "en mi caso me han ayudado un poco con materiales que me vayan a faltar, me apoyan en seguir estudiando y no bajar mis calificaciones" (2018, grupo focal). Otro dijo: "Me ayudan para hacer la guía de la preparatoria” (2018, grupo focal). "A mí solamente me dicen 'ven a los exámenes' y ya” (2018, grupo focal). Uno más mencionó que "a mí también en estudiar y hacer mi tarea" (2018, grupo focal).

Hay beneficiarios que tienen una mayor profundidad y madurez respecto al sentimiento de apoyo que reciben por parte de las organizaciones. "A mí en seguir con la escuela, hacer mis tareas y cuando tengo problemas con la escuela, ellos van y hablan diciendo todo lo que hago aquí, y también cuando necesito alguna persona, los educadores aquí están y me escuchan" (2018, grupo focal). Otro de los jóvenes comentó: “A mí me ayudó más con lo de la hiperactividad y con mis capacidades motrices y también a conocer más amigos" (2018, grupo focal).

Respecto al apoyo que reciben de las organizaciones, otros beneficiarios expresan que no lo ven real: "Yo diría que no" (2018, grupo focal). "No me han ayudado a controlar el enojo" (2018, grupo focal). Hay opiniones con mayor determinación, por ejemplo, que no les han apoyado “en nada” (2018, grupo focal). "En nada, no soy brusco" (2018, grupo focal).

La familia como factor de protección de los jóvenes es fundamental para la prevención de la violencia, delincuencia o la deserción escolar, sin embargo, para algunos que asisten a la organización, hay muestras de que las familias están ausentes en el proceso de socialización y formación, lo que provoca que desde temprana edad tengan que tomar decisiones de adultos.

En algunas organizaciones, los jóvenes expresan que sus familias vigilan el proceso formativo de sus hijos. "En el estudio, me dicen que me ponga a estudiar, que no me quieren en la calle" (2018, grupo focal). Los participantes hablan del apoyo económico y motivacional 


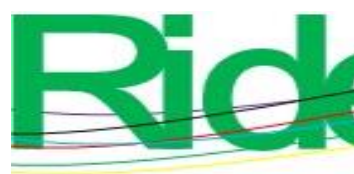

Revista Iberoamericana para la Investigación y el Desarrollo Educativo ISSN $2007-7467$

que les dan en su hogar. "En dinero, pues mi mamá me motivó para que siguiera estudiando" (2018, grupo focal). Y en su momento algunos hablan de motivación "para seguir adelante" (2018, grupo focal). En algunos casos más se habla en concreto de un apoyo económico: "Sí, me dan 250" (2018, grupo focal). Hay jóvenes que mencionan que tienen buena protección familiar: "Bueno, yo diría que, en todo, en que venga a la escuela, se preocupan por mí, en que me levante temprano" (2018, grupo focal).

Hay jóvenes que comentan que la familia cumple un rol de asistencia. Uno de los participantes dijo que de su familia recibía "refugio, comida" (2018, grupo focal). Contrario a esto, dentro de los grupos focales también hubo jóvenes que dijeron que no reciben ningún tipo de apoyos, "en nada"; en su caso, algunas familias les piden a sus hijos que se metan a trabajar (2018, grupo focal).

En el ámbito escolar se observa un descontento generalizado por parte de los jóvenes. Las escuelas no desarrollan mecanismos de integración para jóvenes con problemas familiares, sociales o personales. Básicamente es tolerancia cero: en cuanto cometen algún tipo de violación al reglamento escolar, son expulsados.

La disciplina dentro de los centros escolares es muy estricta. Los jóvenes expresan que por conflictos con compañeros son expulsados de manera inmediata. "En la secundaria tuve problemas, me peleé, y no tenía oportunidad y ya no podía inscribirme en otra, y decidí agarrar una abierta, porque ya no había cupo y por problemas personales" (2018, grupo focal). Otra participante dijo que "a mí me corrieron de la secundaria también, yo porque me peleé con un maestro" (2018, grupo focal).

Hay comentarios donde los jóvenes dicen que ya no los querían en las escuelas y que lo más pronto para resolver el problema fue la expulsión. "No, ya no me querían ahí. Era bien desastroso" (2018, grupo focal). Cabe destacar que aceptan que tenían un comportamiento fuera de las reglas de la escuela, sin embargo, el asunto es generar mecanismos de integración para estos jóvenes que presentan comportamientos distintos. Es necesario realizar una vinculación con la familia, para que la intervención se dé entre la escuela, la familia y el joven. De acuerdo con los jóvenes, ninguno de sus maestros les pregunta sobre la situación dentro de la familia o a nivel personal.

Uno de los temas que es oportuno discutir es el eje de intervención. Sin duda las organizaciones de la sociedad civil quieren hacer cambios en sus usuarios o beneficiarios. Es sabido que los proyectos que se financian por agencias tienen una duración muy corta, a pesar de que los procesos de este tipo deben durar más de una década para percibir cambios, o en su caso, para poder incidir en el comportamiento de las personas. 


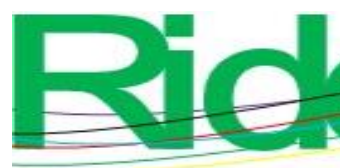

Revista Iberoamericana para la Investigación y el Desarrollo Educativo ISSN $2007-7467$

cambio en sus aspiraciones. Llegar a la universidad no lo es todo, pero es mejor que los jóvenes tengan esa opción de seguir estudiando a ese nivel a que no la tengan. En otras palabras, que los problemas económicos no sean una limitante para los jóvenes; sobre todo, que dentro de las familias de estos jóvenes esté el interés de formar a sus hijos en las universidades. Que las limitaciones culturales no sean un obstáculo. Que el matrimonio a temprana edad no sea la única opción, o que la maquiladora no sea el único espacio para el trabajo.

Una de las preguntas que se hizo a los participantes es sobre las recomendaciones que le hacen a la organización para que haya mayor número de asistentes. Algunos de ellos dijeron que les gustaría “que le pongan ambiente, con música” (2018, grupo focal). Otro de los jóvenes dijo que, en su caso, la organización es un buen espacio para la socialización:

Muchos vienen porque no tienen nada qué hacer en su casa los fines de semana, pero no se dan cuenta que en realidad aquí socializan más, aquí te desestresas un poco, algo distinto a lo normal, porque casi siempre los que están en la mañana: en la mañana es ir a la escuela, en la tarde hacer tarea y pues ya en la tarde salir con mis amigos o dormir; pero es muy distinto salir con esos amigos que tiene uno en la calle a venir con los amigos que están aquí los talleres, porque aquí, realizando la actividad, conversamos más, socializamos más sanamente (2018, grupo focal).

Uno de los ejes temáticos que se abordaron en los grupos focales fueron las aspiraciones. Creemos que es fundamental saber qué les gustaría ser cuando adultos. Hasta el momento, las opiniones de los jóvenes están limitadas por el contexto, sus aspiraciones están marcadas a corto plazo, o en su caso, en actividades técnicas.

Hay jóvenes que no tienen claro en qué les gustaría trabajar cuando crezcan. Algunos de ellos visualizan a la organización de la sociedad civil como un espacio para emplearse. Hay jóvenes que les gustaría desarrollar oficios: "Aún no se lo que me gustaría ser de grande, tal vez mecánico o de electricidad... chofer" (2018, grupo focal). Otros prefieren terminar la secundaria para emplearse en la maquiladora: "Nada más la secundaria para trabajar en la maquiladora" (Participante de grupo focal, Ciudad Juárez, 2018).

También es importante señalar que hay jóvenes que tienen aspiraciones de cursar una carrera profesional: "Pues me gustaría tener una carrera profesional, pero aún no sé cuál” (2018, grupo focal). Otro joven comentó que "aún no sé, estoy entre ser bailarín, diseñador gráfico o enfermero" (2018, grupo focal) 


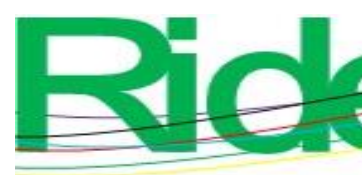

Revista Iberoamericana para la

Investigación y el Desarrollo Educativo

ISSN $2007-7467$

Una de las limitaciones de nuestro trabajo es que la investigación es de carácter cualitativo, lo cual implica que los resultados no pueden generalizarse para todas las organizaciones de la sociedad civil que trabajan con jóvenes. Hay diferentes formas de intervenir con las y los jóvenes en la ciudad, en este caso, los resultados solo son válidos para el contexto donde se hizo el trabajo de campo. Respecto a las fortalezas, se considera que la información recabada en el trabajo de campo es muy relevante porque rescata los testimonios de jóvenes que viven en situación de vulnerabilidad, y en ese sentido, su utilidad serviría para modificar las políticas públicas que se enfocan en este grupo poblacional.

\section{Conclusiones}

Es necesario dejar en claro que el sujeto no es un ser pasivo, activo, racional, sino que tiene una multiplicidad de matices. En un sentido, no podemos hablar de un ser humano universal, tendremos que rescatar a uno con prácticas sociales múltiples. Debemos de construir una intervención social con una visión múltiple que obedezca a los contextos sociales. El objetivo no es construir una intervención social para cada sujeto; nuestra propuesta es diseñar intervenciones sociales que se enfoquen en el cuestionamiento de las prácticas sociales, así como en las estructuras sociales. Creemos que en contextos de vulnerabilidad se requieren de intervenciones sociocríticas.

Debemos de buscar los intereses que cada grupo tiene y clasificarlos en prácticas sociales. De ahí que necesitamos diseñar de manera colectiva las estrategias a desarrollar para realizar la intervención. El diseño de la estrategia de intervención se tendrá que realizar entre los usuarios y el equipo de intervención. En pocas palabras, debemos focalizar la intervención en prácticas sociales, no en el comportamiento. Así pues, el diseño se tendrá que focalizar en experiencias de intervención exitosas, con la intención de modificar, dirigir o cambiar las prácticas sociales que lleven a los sujetos a entornos de derechos sociales.

Entre los temas que hoy trabajan algunas las organizaciones de la sociedad civil en Ciudad Juárez destacan la reivindicación de la diferencia, la exclusión social, educación y el capital social, e incluso trabajan en el orden de grupos, como niños, jóvenes, mujeres, adultos mayores. Lo que actualmente están tratando los organismos internacionales, agencias financiadoras y algunas instituciones del Estado con las organizaciones de la sociedad civil es que estas sirvan para integrar en el sistema a una parte de la sociedad que ha sido marginado del sistema económico global; pero solo son acciones asistenciales, por lo que se requieren de intervenciones sociales a largo plazo que permitan el cuestionamiento de prácticas sociales de riesgo para las y los jóvenes. 


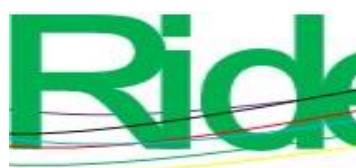

Revista lberoamericana para la Investigación y el Desarrollo Educativo ISSN $2007-7467$

En relación con las contribuciones a futuras líneas de investigación, nos centraremos en un análisis cuantitativo. La idea es generar un modelo estadístico que permita saber las condiciones sociales y familiares que permitan cambios sociales en el comportamiento de las y los jóvenes en contextos de violencia.

\section{Referencias}

Aigneren, M. (2002). La técnica de recolección de información mediante los grupos focales. La sociología en sus escenarios. (6). Recuperado de https://revistas.udea.edu.co/index.php/ceo/article/view/1611.

Arnedo, J., Díaz, D. y González, B. (2016). Sistematización de la experiencia del proyecto de intervención social con las/os adolescentes y jóvenes potencializando sus capacidades y fortalezas para mejorar la convivencia familiar y social a través de la reconstrucción de sus proyectos de vida en el barrio Villas de Aranjuez. (informe de sistematización). Universidad de Cartagena, Cartagena de Indias.

Berger, P. L. y Luckmann, T. (2003). La construcción social de la realidad. Argentina: Amorrortu editores.

Bermúdez, C. (2010). Intervención social y organizaciones comunitarias en Cali. Prospectiva: Revista de Trabajo Social e Intervención Social, (15), 49-68.

Borgianni, E. y Montaño, C. (orgs.) (2000). Metodología y servicio social. Hoy en debate. Sao Paulo, Brasil: Cortez Editora.

Callado, R. y Martínez, N. (2017). Transición a la edad adulta en jóvenes vulnerables. Efectos de una intervención sociocomunitaria en el barrio de Las Remudas, Gran Canaria, España. Enfermería Global, 16(4), 284-323.

Carballeda, A. (2012). La intervención en lo social. Exclusión e integración en los nuevos escenarios sociales. Buenos Aires, Argentina: Paidós.

Díaz, E. G. y Silva, B. E. (2018). Proyecto de intervención psicosocial "Desnaturalizando la violencia", con jóvenes del estado de Coahuila. Alternativas en Piscología, (38), 8-21.

Diputació Barcelona. (2009). Modelo de prevención y detección de situaciones de riesgo social en la infancia y la adolescencia. Barcelona, España: Diputació Barcelona.

Escudero, V. (2011). Adolescentes y familias en conflicto. España: Fundación Meniños.

Freire, P. (1976). La educación como práctica de la libertad. España: SXXI. 


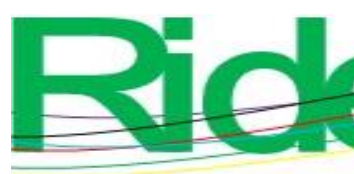

Revista Iberoamericana para la Investigación y el Desarrollo Educativo ISSN $2007-7467$

Gallardo, R. M. (2006). ¿Cómo intervenir con los y las adolescentes con problemas de conducta? Estrategias multidisciplinares de intervención. Una visión desde el sistema educativo. Intervención presentada en el Seminario Formativo "Violencia y Adolescencia con Problemas de Comportamiento". Bilbao, 28 de febrero de 2006.

Goffman, E, (1979). Relaciones en público. Microestudios de orden público. Madrid, España: Alianza.

Guerra, Y. (2007). La instrumentalidad del servicio social, sus determinaciones sociohistóricas y sus racionalidades. Sao Paulo, Brasil: Cortez Editora.

Losada, S. (2016). Metodología de la intervención social. España: Editorial Síntesis.

Molina, A. (29 de enero de 2019). Artistas y sociólogos con cámara. El País. Recuperado de https://elpais.com/cultura/2019/01/24/babelia/1548325207_682184.html.

Montaño, C. (2000). La naturaleza del servicio social (2. ${ }^{\mathrm{a}}$ ed.). Sao Paulo, Brasil: Cortez Editora.

Montaño, C. (2004). Hacia la construcción del Proyecto Ético-Político-Profesional crítico. Documento presentado en el XVIII Seminario Latinoamericano de Escuelas de Trabajo Social. Costa Rica, julio de 2004.

Montaño, C. (2007). Trabajo social e intervención: La politización de la acción profesional. Conferencia presentada en el VII Coloquio Internacional de Estudiantes de Trabajo Social. Puno, 2007.

Mori, M. (2008). Una propuesta metodológica para la intervención comunitaria. Liber, (14), 81-90.

Netto, J., (1997). Capitalismo monopolista y servicio social. Sao Paulo, Brasil: Biblioteca Latinoamericana de Servicio Social y Cortez Editora.

Paz, R. y Unás, V. (2010). Fisuras en los discursos de la intervención social contemporánea. Revista CS, (1), 217-237.

Poza, F., Fernández, A. y Ferreira, J. P. (2017). Buenas prácticas de intervención social en relación al ocio con jóvenes en riesgo de exclusión desde la percepción de los agentes sociales. OBETS. Revista de Ciencias Sociales, 12(Extra 1), 203-228.

Poza, F., Fernández, A. y Ferreira, J. P. (2018). La práctica profesional de los agentes sociales en materia de ocio juvenil: estrategias para la intervención. Pedagogía Social. Revista Interuniversitaria, (31), 93-105.

Ruiz, E. (2010). Para entender la intervención social. En Blanco, J., Hernández, M., Avila, M. y García, F. (coords.), Paradojas y geometrías en intervención social (pp. 15-32). España: Aconcagua Libros.

Sáenz, J. (2008). Temas de reflexión en la intervención social. Revista CS, (1), 189-215. 